\title{
Management of miller class II gingival recession by laterally positioned pedicle flap revised technique
}

Accepted: $13 / 10 / 2016$

Dildar Abdullah Othman*

\section{Abstract}

Background and objective: Gingival recession is the apical migration of the gingival margin from its normal position on the crown of the tooth to the root apically beyond the cemento-enamel junction which can cause major functional and esthetical problems. It has been clinically related to higher incidence of root caries, attachment loss, hypersensitivity and esthetic related problems. The goal of this study was to evaluate the effective of a modification of surgical procedure to laterally repositioned flap for coverage of isolated recession.

Methods: A total of 25 patients with miller class II gingival recession attended the Department of Periodontology in the College of Dentistry, Hawler Medical University for treatment of their problem. Their gingival recession about 2 to $5 \mathrm{~mm}$ in the lower anterior teeth with shallow vestibule. After full preparation of patient which include scaling and polishing and root planning the laterally displaced revised flap technique were done. Patients were followed up in 2 week and 3 month interval to see the changes after treatment during this period. These parameter were taken pocket depth, clinical attachment loss and gingival recession which can be measured by the distance from CEJ to the base of pocket.

Result: In the recipient side, the mean gingival recession was about $3.2 \mathrm{~mm}$ at base line, after 2 weeks the mean gingival recession became $0.6 \mathrm{~mm}$ and after 3 months it became $0.38 \mathrm{~mm}$. In the donor side, the mean gingival recession was $0 \mathrm{~mm}$ at base line. After 2 weeks the mean gingival recession became $1.05 \mathrm{~mm}$ and after 3 months it became $0.5 \mathrm{~mm}$.

Conclusion: It can be concluded that laterally displaced revised flap technique in localized recession defects can be used to restore the esthetic and functional properties of labial gingiva of teeth by repairing gingival defect.

Keywords: Gingival recession; Revised flap technique; Esthetic; Functional properties

\section{Introduction}

Gingival recession is the exposure of cementum on facial surfaces of teeth, may occur on single or multiple teeth. ${ }^{1}$ Gingival recession can be occurring by the apical migration of the gingival margin from its normal position on the crown of the tooth to levels on the root surface beyond the cemento-enamel junction. $^{2}$ Marginal tissue recession can cause major functional and esthetic problems. It has been clinically related to higher incidence of root caries, attachment loss, hypersensitivity and smile related concerns. Many factors have been implicated in the etiology, including plaque, position of the tooth in the arch, faulty tooth brushing, traumatic occlusion, high frenum or muscle attachments, lack in dimension of gingiva, lip pressure, etc $^{1}$. The sequelae of gingival recession consists of a non-keratinized tissue not firmly bound to the underlying periosteum and ill designed to withstand daily insults of tooth brushing and masticatory forces. ${ }^{3}$ Several procedures have been proposed to preserve or enhance patient esthetics. Multiple surgical procedures have been developed to obtain predictable esthetic root coverage. The laterally positioned flap is commonly used to cover isolated,

* Department of Periodontology, College of Dentistry, Hawler Medical University, Erbil, Iraq. 
denuded roots that have adequate donor tissue laterally and vestibular depth. ${ }^{4}$ The literature has documented that gingival recession can be successfully treated by means of several mucogingival surgical approaches irrespective of the technique utilized, provided that the biologic conditions for accomplishing root coverage are satisfied with no loss of soft and hard tissue height interdentally. ${ }^{5} \mathrm{~A}$ graft is a piece of living tissue or synthetic material placed in contact with injured tissue to repair a defect or correct a deficiency. ${ }^{2}$ There are currently different techniques for root coverage which includes pedicle grafts, free gingival grafts, connective tissue grafts and Guided tissue regeneration (GTR). Bouchard et al" performed sub epithelial connective tissue grafts in areas of gingival recession. ${ }^{6}$ Grupe and Warren, ${ }^{7} 1956$ proposed the technique of laterally repositioned flap operation for coverage of isolated recessions. The indications of laterally positioned flap are the presence of sufficient width, length and thickness of keratinized tissue adjacent to the area of gingival recession, This method is most suitable for root coverage in gingival recession with narrow mesiodistaldimension. $^{8}$ Guinard and Caffese $^{9}$ reported an average of $1 \mathrm{~mm}$ of post operative recession on the adjacent donor site, The disadvantages of this method are possible bone loss and gingival recession in donor site. The goal of the present study was to evaluate the effectiveness of a modified surgical approach to laterally repositioned flap for coverage of isolated recession.

\section{Methods}

Twenty five patients attended to periodontology department, College of dentistry - Hawler medical university with chief complaint of gingival recession and sensitivity of lower anterior teeth and some complaint from esthetic problem (Figure 1). On clinical examination a class II miller classification was present at their teeth in lower anterior teeth on labial aspect along with shallow vestibule. Their clinical attachment loss ranged between 3 to $6 \mathrm{~mm}$ and the distance between cementoenamel junction and gingival margin was ranged $2-5 \mathrm{~mm}$ and the distance between gingival margin and base of pocket was ranged between 1 to $2 \mathrm{~mm}$.

\section{Presurgical preparation}

A general assessment of patient was made through history and routine laboratory investigations. The surgical procedure was explained to the patient and the informed consent obtained. Preparation of the patient included scaling and root planing and oral hygiene instructions. Brushing technique was prescribed to the patient.

\section{Parameters assessed}

Parameters were assessed with UNC-15 periodontal probe. Following parameters were assessed at baseline and 2 week and 3 months after the surgical procedure. Clinical recession depth (RD) - distance between cemento-enamel junctions to the most apical point of gingival margin. Pocket depth (PD) - distance between the gingival margin and the bottom of the

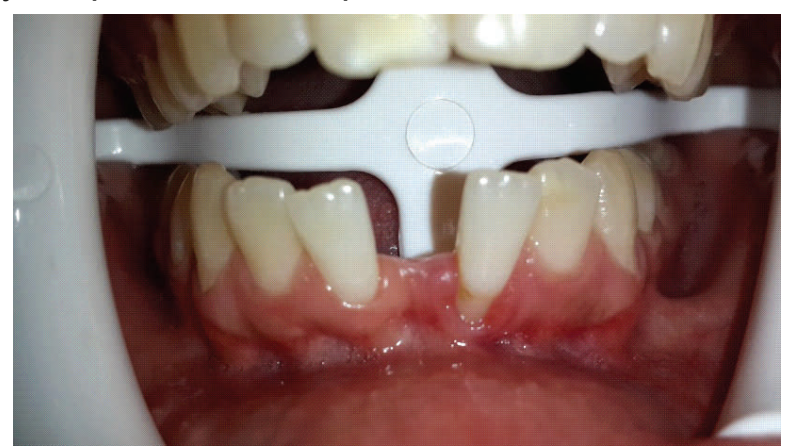

Figure 1: Preoperative view. 
gingival sulcus. Clinical attachment level $(C A L)$ - measured from the cemento enamel junction to the bottom of the pocket. Clinical photograph was taken before and after the operation. The clinical parameters described were similarly recorded as indicated during follow up periods after surgery.

\section{Surgical procedure}

Laterally positioned pedicle flap-revised technique was done. After proper isolation of the surgical field, the operative sites were anesthetized using $2 \%$ lidocaine hydrochloride with adrenaline (1:200000). A collar of tissue was removed around the recession by two vertical incisions, which joined at one point apical to the base of the recession which is $v$ shape incision lined $a$ receded area. Then the second incision is done horizontally from recession area to a vertical incision which is extending from gingival margin to the oral mucosa up to the level of the base of central incisor with a \#15 blade then the last incision was done as oblique releasing incision from mucosa. After that, thorough scaling and root planning was performed. The sliding flap detached as follows: First, the one-half of the flap away from the recession was reflected as a split thickness flap by giving sharp dissection using \#15 blade, and then one half of the flap close to the recession was reflected as full thickness flap by giving blunt dissection using periosteal elevator. Then the entire flap was finally released by performing an undermining incision through the periosteum at its apical base. Then Collar of tissue was removed around the recession site then Combined partial and full thickness flap elevated after that the flap was displaced laterally and adapted in recepient site (Figure 2). Then the flap was sutured in new position by using 4.0 silk suture (Figure 3 ).

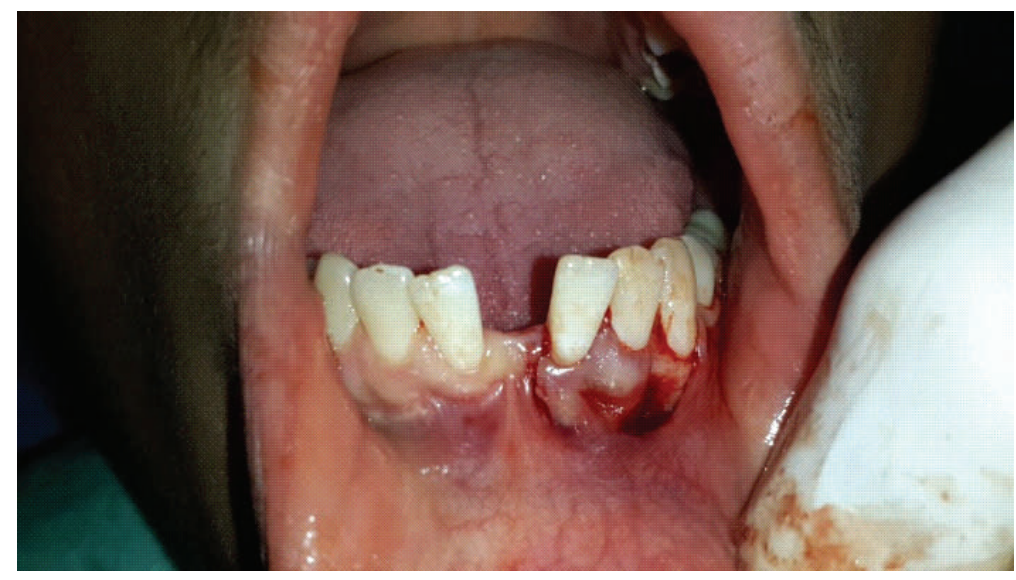

Figure 2: Flap adapted in recipient site.

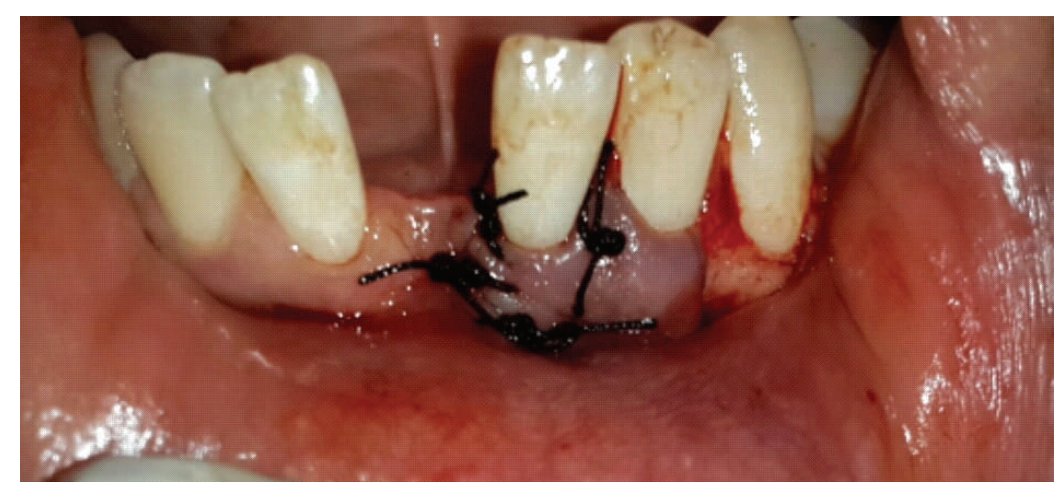

Figure 3: Flap was sutured. 
Finally periodontal pack (dressing) coe pack was placed over surgical site both recipient and donarsite (Figure 4).

\section{Post-Operative care}

Amoxiclav $625 \mathrm{mg}$ thrice a day was prescribed for 5 days. Ibuprofen $400 \mathrm{mg}$ thrice daily and vitamin-B complex, 1 capsule daily were also prescribed for 5 days. Patient was recommended to follow all the normal oral post-operative hygiene instructions. Patient should rinse the oral cavity with $0.12 \%$ chlorhexidine digluconate mouth rinse for two weeks. Patient was advised to avoid pulling on their lips to observe the surgical site. Both dressings and sutures were removed 7-10 days after surgery (Figure 5). Post-operative follow-up was done for 2 weeks and 3 months (Figure 6). In these cases, there were no post-operative complication and healing was satisfactory. The patients did not have any post-operative morbidity. Then cases followed up after 3 month (Figure 6)

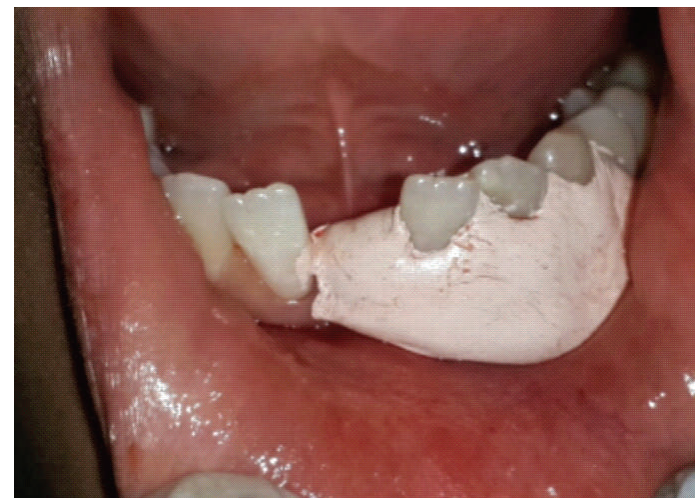

Figure 4: Periodontal pack placement.

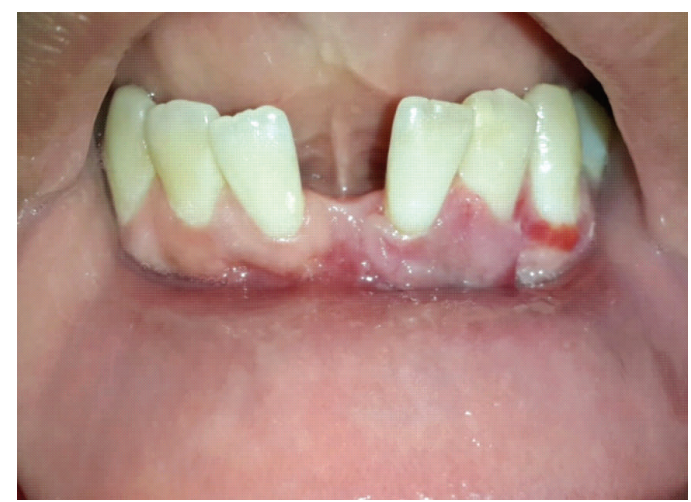

Figure 5: Follow up after 2 weeks.

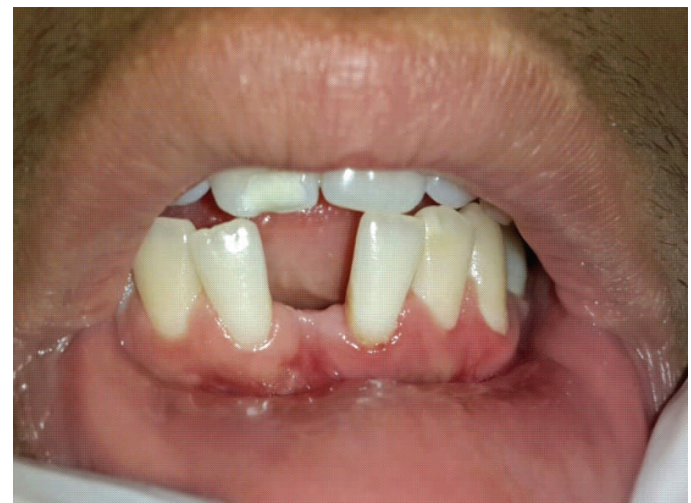

Figure 6: Follow up after three months. 


\section{Statistical analysis}

Data were entered and analyzed using the statistical package for the social sciences (SPSS). Paired t-test was used to compare between means of gingival recession before and after three months of surgical intervention. A $P$ value equal or less than 0.05 was considered as statistically significant

\section{Results}

At base line the mean gingival recession was about $3.2 \mathrm{~mm}$ and $\mathrm{CAL}$ was about $4.3 \mathrm{~mm}$ and PPD was about $1.1 \mathrm{~mm}$ after three month follow up after operation the surgical side gain about $2.8 \mathrm{~mm}$ reduction in gingival recession and gain about $3 \mathrm{~mm}$ in clinical attachment. According to $p$ value which is analyzed by paired t-test there is a highly significant difference between the cases before intervention and after three months treatment (Table 1). While at donor site before surgery there was no gingival recession but after operation the site was receded about $0.5 \mathrm{~mm}$. According to $P$ value which is analyzed by paired t-test, there was a highly significant difference between the cases before intervention and after three months treatment (Table 2).

\section{Discussion}

Laterally positioned flaps have been widely used since Grupe and Warren' introduced method for the treatment of localized gingival recession. In this procedure, the adjacent keratinized gingiva is positioned laterally, and the exposed root surface in the localized gingival recession is covered. The disadvantages of this method are possible bone loss and gingival recession on the donor site. Guinard and Caffesse" reported an average of $1 \mathrm{~mm}$ of postoperative gingival recession on the adjacent donor site. ${ }^{10}$ Complete root coverage is the primary objective to be accomplished when treating gingival recession in patients with aesthetic demands. Many root coverage procedures have been widely accepted in clinical dental practice like GTR, free gingival grafts, connective tissue grafts, etc. Grupe and Warren in 1956 suggested that laterally repositioned flap has shown to be the most successful procedure for the treatment of gingival recession. ${ }^{11}$ Lateral sliding flap technique first described by Harvey (1970). ${ }^{12}$ for management of localized gingival recession as a modification of This flap is elevated from

Table 1: show the difference in the level of recession at recipient site.

\section{RECEPIENT SIDE}

\begin{tabular}{cccccccccc}
\multicolumn{3}{c}{ Before surgery } & \multicolumn{2}{c}{$\mathbf{2}$ week after surgery } & \multicolumn{3}{c}{$\mathbf{3}$ month after surgery } & $\boldsymbol{P}$ value \\
\hline CAL & recession & $\begin{array}{c}\text { Pocket } \\
\text { depth }\end{array}$ & CAL & recession & $\begin{array}{c}\text { Pocket } \\
\text { depth }\end{array}$ & CAL & recession & $\begin{array}{c}\text { Pocket } \\
\text { depth }\end{array}$ & \\
4.3 & 3.2 & 1.1 & 1.5 & 0.61 & 1.05 & 1.2 & 0.38 & 1 & $<0.001$ \\
\hline
\end{tabular}

Table 2: show the difference in the level of recession at donor site.

DONOR SIDE

\begin{tabular}{ccccccccccc}
\multicolumn{4}{c}{ Before surgery } & \multicolumn{4}{c}{ 2 week after surgery } & \multicolumn{2}{c}{ 3 Month after surgery } & P value \\
\hline CAL & recession & $\begin{array}{c}\text { Pocket } \\
\text { depth }\end{array}$ & CAL & recession & $\begin{array}{c}\text { Pocket } \\
\text { depth }\end{array}$ & CAL & recession & $\begin{array}{c}\text { Pocket } \\
\text { depth }\end{array}$ & \\
0.05 & 0 & 1 & 1.8 & 1.05 & 1 & 1.2 & 0.5 & 1 & $<0.001$ \\
\hline
\end{tabular}


donor zone as full thickness in the mesial portion of the flap (near the recession) and a split thickness on the distal portion (away from the recession). The objective of full thickness (mucoperiosteal) flap design in the mesial portion of flap is to place periosteum over the exposed root to utilize its potentially dynamic reparative potential to provide more tenacious connective tissue-cementum fixation of the flap. Periosteum of the mucoperiosteal flap (mesial side of flap design), recipient site periodontal ligament, periosteum, endosteum, and lamina propria surrounding the lesion can provide fibrogenic, osteogenic, cementogenic, vascular proliferative and neural trophic activity, which all play important role in healing of the periodontal surgical wound and partial thickness flap (distal side of flap design) avoid the exposure of the bone at donor site. ${ }^{11}$ However, it is important to emphasize that all the root coverage procedures have been demonstrated to heal with a long junctional epithelium, and regeneration has been observed only in the most apical portion of the lesion. ${ }^{13}$ This laterally displaced flap revised technique has been demonstrated to be a reliable and predictable treatment modality for obtaining root coverage in an isolated gingival recession. The advantages of this technique are reduced hypersensitivity, esthetic color matching, good blood supply to the reflected flap with high mean percentage of root coverage, ${ }^{14}$ These root coverage outcomes were associated with significant clinical attachment gain with reduction in probing pocket depth. ${ }^{15}$ However there are still many limitations, which need to be considered when this technique is applied. These include the following:

-The attached gingiva adjacent to the area of the recession should be adequate thick, since a cause-effect relationship has been reported to exist between flap thickness and recession reduction.

-There should be no deep periodontal pockets and bone loss beyond the mucogingival junction at the adjacent areas of the affected tooth.

-Separate surgical procedures are still needed in presence of multiple adjacent recessions.

The analysis of the literature revealed that the limiting condition for performing this approach, as a root coverage surgical procedure was the need for adequate keratinized tissue lateral to the recession defect. Previous studies did not quantify the minimum width and height of keratinized tissue, which must be present lateral to gingival defects in order to render this approach a predictable root coverage surgical procedure. A certain amount of the lateral keratinized tissue, infact must be preserved in situ to prevent gingival recession at the donor site, while the remaining part is used to cover the exposed root surface and the adjacent connective tissue beds. ${ }^{16}$ This present study demonstrated that the proposed modification of the laterally displaced flap is an effective treatment modality for the management of recession defects affecting teeth in esthetic regions of the mouth. Infact this surgical technique resulted in complete root coverage in the treated cases.

\section{Conclusion}

Within the limits of the study, it may be concluded that laterally positioned pedicle flap-revised technique in localized recession defects can be used to restore the functional properties of labial gingiva of teeth by repairing gingival defect and re-establishing the continuity and integrity of zone of keratinized gingiva.

\section{Conflicts of interest}

The author reports no conflicts of interest.

\section{References}

1. Bjorn UZ. Orthodontics and periodontics. In Jan Lindhe, Thorkild Karring, Niklaus P. Lang Editors. Clinical periodontology and implant dentistry. $4^{\text {th }}$ ed. UK: Blackwell Munksgaard; 2003. p.765-6.

2. Loe $H$, Anerud $A$, Boysen $H$. The natural history of periodontal disease in man: Prevalence, severity, and extent of gingival 
recession. J Periodontol 1992; 63:489-95.

3. Prichard JF. Glossary of terms. J Periodontol 1987; 15(2):51-4.

4. Carranza S. Clinical Periodontology. In: Newman MG, Takei HH, Klokkevold PR, Carranza FA, editors. $10^{\text {th }}$ ed. ST. Louis, Missouri: Saunders Publication; 2006. p. 1016.

5. Vijayaraghavan A, Rajaram V, Bhavna J, Thyagarajan R, Vikram B. Double laterally rotated bilayer flap operation for treatment of gingival recession: A report of two cases. J Indian Soc Periodontol 2008; 12(2):51-4.

6. Bouchard P, Etienne D, Ouhayoun J, Nilveus R. Subepithelial connective tissue grafts in the treatment of gingival recessions: A comparative study of 2 procedures. J Periodontol 1994; 65:929-36.

7. Grupe HE, Warren RF. Repair of gingival defects by sliding flap operation. J Periodontol 1956; 27:92-5.

8. Jagmohan S, Vipin B. Laterally positioned flap - revised technique along with platelet rich fibrin in the management of miller class II gingival recession. Dent Res J 2013; 10(2):268-73.

9. Guinard EA, Caffese RG. Treatment of localized gingival recession part-I Lateral sliding flap. J Periodontol 1978; 49:351-6.

10. Naoshi S. Increasing attached gingiva. In periodontal surgery (a clinical atlas). Chicago: Quintessence Publishing Co; 2000. p. 342-6.

11. Grupe HE. Modified technique for lateral sliding flap operation. J Periodontol 1966; 37:491-5

12. Harvey PM. Surgical reconstruction of the gingiva. Part II. Procedures. N Z Dent J 1970; 66:42-52.

13. De waal $H$, Kon $S$, Ruben MP. The laterally positioned flap. Dent Clin North Am 1988; 32:267-85.

14. Ramjford $\mathrm{S}$. The lateral sliding flap with free gingival grafts. The University of Michigan, School Of Dentistry; 1971.

15. Smukler H. A laterally positioned mucoperiosteal pedicle graft in the treatment of denuded roots. J Periodontol 1976; 47:590-5.

16. Johnson RH. Guided tissue regeneration. Atlas of cosmotic and reconstructive periodontal surgery. Edward. S. Editors. Third ed. Shelton, Connecticut: People's Medical Publishing House; 2009. p. 159-3. 